\title{
Características anatômicas e morfométricas do ligamento oblíquo do cotovelo de equiinos
}

\author{
Anatomical and morphometrical characteristics of the oblique ligament of the equine elbow
}

\author{
María Cristina Hernández-Tovar ${ }^{1}$ Silvana Martinez Baraldi-Artoni ${ }^{1 *}$ \\ José Wanderley Cattelan ${ }^{2}$ Daniela Oliveira ${ }^{1}$
}

\section{RESUMO}

\begin{abstract}
Neste trabalho, algumas características anatômicas e morfométricas do ligamento oblíquo do cotovelo do eqüino foram descritas em dez animais adultos, sem raça definida, que não apresentavam afecções dos órgãos locomotores. O ligamento oblíquo origina-se dorsal à fossa radial do úmero, atravessa obliquamente a superfície cranial do cotovelo e se divide em uma porção longa, que se insere na tuberosidade radial, e em outra curta, que se une à porção longa do ligamento colateral medial. Foram efetuadas medidas visando a obter o comprimento e a largura máximas entre a origem e a inserção do ligamento oblíquo, não sendo observadas diferenças $(P>0,05)$ nas comparações feitas entre os sexos e os antímeros. O ligamento oblíquo contribui no efeito mola e na manutenção da estabilidade da articulação do cotovelo do eqüino. Pela particularidade de sua localização, cranial à articulação, o ligamento oblíquo possui ação frenadora, impedindo a extensão completa da referida articulação.
\end{abstract}

Palavras-chave: artrologia, cotovelo, eqüino, morfologia.

\section{ABSTRACT}

Some anatomical and morphometrical characteristics of the equine elbow oblique ligament were described in ten adult mongrel animals that did not present locomotor diseases. The oblique ligament arises dorsal to the radial fossa of the humerus, it crosses obliquely the elbow cranial surface and it becames separated in a long portion that attaches to the radial tuberosity and a short portion that joins to the long portion of medial collateral ligament. Measurements of the lenght and width were taken between origin and insertion of the oblique ligament, without differences $(P>0.05)$ being observed when sexes and limbs were compared. The oblique ligament acts in the spring effect and in the stability maintenance of the equine elbow joint. By the particularity of its location cranial to the joint, the oblique ligament has a restrain action, hinding complete extension of the equine elbow.

Key words: arthrology, elbow, equine, morphology.

\section{INTRODUÇÃO}

Os ligamentos são estruturas especializadas que ligam os ossos entre si, promovendo estabilidade das articulações, e servem de guia para o movimento articular. São peças de tecido conjuntivo denso compostas por fibras colágenas que fornecem alta resistência à tração (BENJAMIN \& RALPHS, 1997).

A principal função dos ligamentos é prevenir movimentos excessivos ou anormais, além de manter a estabilidade das articulações pela sua função proprioceptiva (BENJAMIN \& RALPHS, 1997). Os ligamentos, segundo sua localização, podem ser intracapsulares ou extracapsulares. Os ligamentos intracapsulares (intra-articulares) são encontrados dentro das articulações e são rodeados pela membrana sinovial. Os ligamentos extracapsulares (periarticulares) são externos à cápsula articular (DYCE et al., 1997; FRANDSON et al., 2005).

O cotovelo dos eqüinos é um gínglimo típico, com movimentos de flexão e extensão. A articulação é formada pelas extremidades distal do úmero e as proximais do rádio e da ulna. A cápsula articular é fina, forma uma bolsa na fossa do olécrano sob o músculo

${ }^{1}$ Departamento de Morfologia e Fisiologia Animal, Faculdade de Ciências Agrárias e Veterinárias (FCAV), Universidade Estadual Paulista (UNESP), 14884-900, Jaboticabal, SP, Brasil. E-mail: smbart@fcav.unesp.br. * Autora para correspondência.

${ }^{2}$ Departamento de Clínica e Cirurgia Veterinária, FCAV, UNESP, Jaboticabal, SP, Brasil. 
ancôneo e uma almofada de gordura. Ela também está aderida aos tendões dos músculos que surgem da extremidade distal do úmero e terminam na extremidade proximal do rádio. A extensão completa é evitada pela tensão dos ligamentos colaterais e pelo músculo bíceps do braço, que possui o eixo do movimento ligeiramente oblíquo (PAIVA, 1953; SISSON, 1986).

Os tratados clássicos de Anatomia veterinária descrevem somente os ligamentos colaterais lateral e medial na articulação do cotovelo do eqüino (SISSON, 1986; DYCE et al., 1997), havendo poucas informações sobre o ligamento oblíquo e estas, quando encontradas, referem-se ao do cão (OLIVEIRA, 2002, 2004). Assim, diante da importância desta articulação nos eqüinos, o objetivo desta investigação é estudar o ligamento oblíquo, destacando-se suas características anatômicas e morfométricas.

\section{MATERIAL E MÉTODOS}

Foram utilizados os cadáveres de dez eqüinos (cinco machos e cinco fêmeas), adultos, sem raça definida, que não apresentavam afecções dos órgãos locomotores.

Os membros torácicos direito e esquerdo foram separados do corpo do animal, removendo-se o tecido cutâneo e os ossos escápula, carpo, metacarpo, falanges e sesamóides, deixando as peças anatômicas constituídas pela articulação do cotovelo e músculos contígüos, que foram fixados em solução de formol a $10 \%$.

Por meio da macroscopia, foram registrados os pontos de origem e inserção do ligamento oblíquo dos cotovelos direitos e esquerdos e observadas suas relações com a cápsula articular e com a porção longa do ligamento colateral medial. Usando um paquímetro e uma régua milimetrada, foram feitas medidas entre a origem e a inserção do ligamento oblíquo, visando a obter o comprimento e a largura máximas de cada ligamento.

Os dados obtidos foram avaliados estatisticamente utilizando a análise de variância, e as médias foram comparadas pelo teste de Tukey por meio de programa computacional SAS (2004), considerandose o nível de significância de 5\%.

\section{RESULTADOS E DISCUSSÃO}

Os meios de união da articulação do cotovelo de eqüino são constituídos pela cápsula articular e pelos ligamentos oblíquo e colaterais lateral e medial. A cápsula articular compõe-se de uma camada fibrosa, de desenvolvimento e resistência variáveis, de acordo com a exigência mecânica do local e uma membrana sinovial (LIEBICH \& KÖNIG, 2002).

A cápsula articular envolve as duas articulações observadas no cotovelo e forma três fundos cegos: um lateral para o tendão do músculo ulnar lateral, um medial para os músculos flexores radial do carpo, ulnar do carpo, superficial dos dedos e profundo dos dedos e outro intermediário, que corresponde à fossa do olécrano, situado sob o músculo ancôneo, como foi observado por PAIVA et al. (1953).

As observações anatômicas realizadas nas diferentes estruturas do cotovelo denotam a importante função estática e dinâmica que os ligamentos oblíquo e colaterais lateral e medial desempenham na união e na estabilidade da articulação, corroborando as observações de BENJAMIN \& RALPHS (1997). Observou-se que a tróclea do úmero articula-se de duas maneiras, por um lado com a incisura troclear ulnar e, por outro, com a fóvea da cabeça do rádio. Dessa forma, assim como mencionado por LIEBICH \& KÖNIG (2002), a articulação compõe-se das articulações umeroulnar e umerorradial.

O ligamento oblíquo é bem desenvolvido e seus feixes encontram-se intimamente aderidos à membrana fibrosa da cápsula articular umerorradial, que recebe o reforço de fibras tendíneas, na sua porção látero-proximal, do músculo extensor radial do carpo e, na sua porção médio-distal, do músculo bíceps braquial. O ligamento oblíquo origina-se dorsal à fossa radial do úmero, atravessa obliquamente a superfície cranial do cotovelo e se divide em duas porções: uma longa, (Figura 1) que se insere na tuberosidade radial, localizada na epífise proximal do rádio, contornando o tendão de inserção do músculo bíceps braquial, e outra curta, que se une à porção longa do ligamento colateral medial (Figuras 1 e 2) e apresenta um coxim adiposo, que se localiza próximo às regiões de origem e inserção (Figura 1).

Os dados relatados sobre a origem e a inserção do ligamento oblíquo do cotovelo dos eqüinos se assemelham às observações de PAIVA (1953), embora este ligamento não seja descrito em livros-textos de Anatomia, como SISSON (1986); DYCE et al. (1997), ou, ainda, em tratados de nomenclatura anatômica (SCHALLER, 1999). Pesquisas feitas no cão descrevem a divisão deste ligamento em duas porções, uma cranial ou longa e outra caudal ou curta, a qual se funde à porção cranial (longa) do ligamento colateral medial (OLIVEIRA, 2002, 2004), o que também foi observado neste estudo. OLIVEIRA (2004) atribui um papel importante do ligamento oblíquo na estabilidade da articulação do cotovelo do cão, já que favorece a integridade, aumenta a resistência à tração e facilita a 


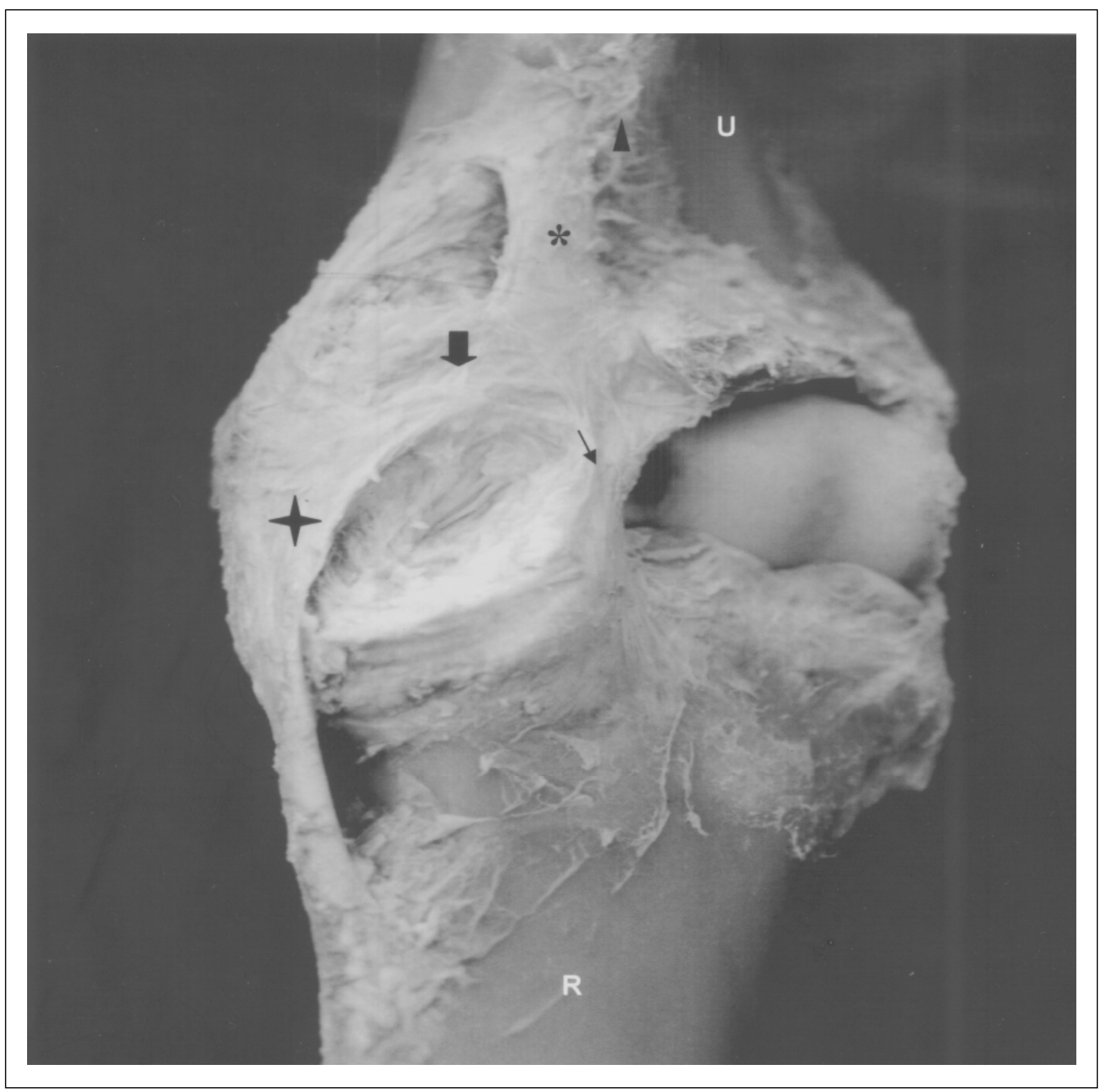

Figura 1 - Vista cranial de preparação anatômica do cotovelo de eqüino,. Observar ligamento oblíquo $(*)$, porção longa do ligamento oblíquo ( $\square$ ), porção curta do ligamento oblíquo ( $\square$ ), porção longa do ligamento colateral medial ( $\uparrow$ ), coxim adiposo $(\mathbf{\Delta})$, úmero $(\mathrm{U})$ e rádio $(\mathrm{R})$.

reconstrução do ligamento colateral medial; contudo, nos eqüinos, a mensuração da contribuição fornecida à estabilidade da articulação do cotovelo pela união das fibras das duas porções destes ligamentos necessita de investigações adicionais.

Ao verificar a distribuição do coxim adiposo ao redor do ligamento oblíquo do eqüino, pôde-se observá-lo em concentrações maiores nas regiões de origem e inserção, provavelmente para reduzir o atrito entre o ligamento e os ossos e favorecer seu deslizamento.
Pelo fato do ligamento oblíquo do cotovelo do eqüino encontrar-se aderido à membrana fibrosa da cápsula articular, pode-se classificá-lo como ligamento extracapsular (DYCE et al., 1997; FRANDSON et al., 2005).

As médias e desvios-padrão obtidos nas medidas dos comprimentos e das larguras do ligamento oblíquo encontram-se na tabela 1. Não foram observadas diferenças $(\mathrm{P}>0,05)$ nas comparações feitas entre os sexos e os antímeros. 


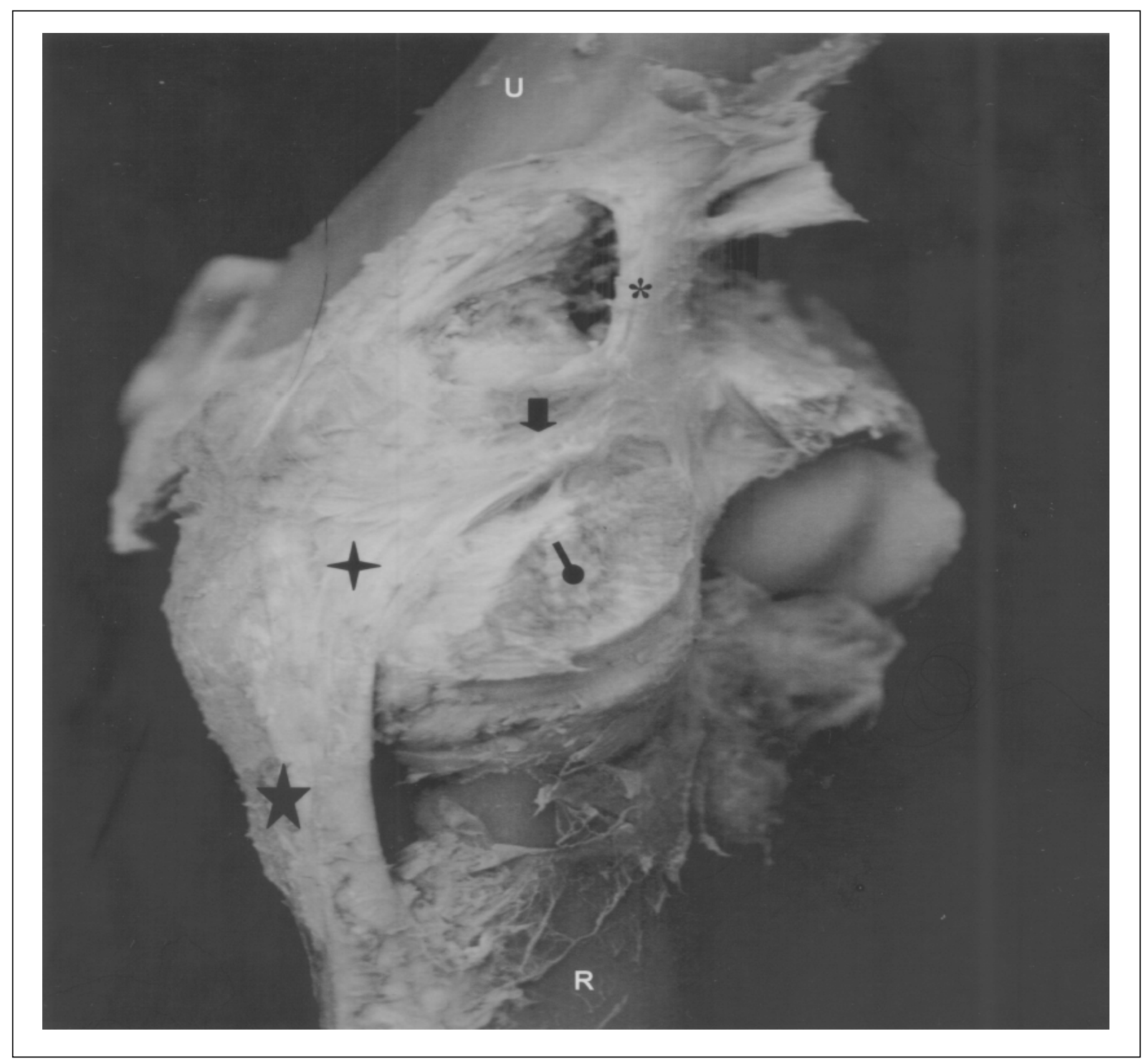

Figura 2 - Vista crânio-medial de preparação anatômica do cotovelo de eqüino. Notar ligamento oblíquo (*), porção curta do ligamento oblíquo $(\square)$ ), ligamento colateral medial $(\star)$, porção longa do ligamento colateral medial $(\downarrow)$, músculo bíceps braquial ( $)$

LIEBICH \& KÖNIG (2002) afirmam que o cotovelo é uma articulação troclear, classificada como gínglimo, e a inserção dos ligamentos colaterais no eixo transversal permite que essa juntura funcione como uma articulação em mola nos eqüinos. A realização passiva dos movimentos de extensão e flexão se simplifica e se reduz à ação de início do deslocamento das alavancas ósseas até determinado grau de angulação, além do qual sobrevém violento e espontâneo movimento dessas alavancas, completando-se assim o fechamento ou a abertura articular (PAIVA, 1953).
PAIVA (1953) descreve que a maior parte dos feixes fibrosos componentes dos ligamentos colaterais lateral e medial situa-se caudal ao raio correspondente à máxima excentricidade da superfície articular umeral. Esta circunstância explica a tendência do úmero a colocar-se no direto prolongamento do rádio, no que é obstado pelo ligamento oblíquo. Devido à localização do ligamento oblíquo, cranial à articulação, infere-se que este ligamento atue como um elemento frenador do movimento de extensão, limitando a amplitude do disparo da articulação e atenuando o impacto do processo ancôneo à fossa do olécrano. A

Ciência Rural, v.36, n.6, nov-dez, 2006. 
Tabela 1 - Médias e desvios padrões dos comprimentos e larguras (cm) do ligamento oblíquo do cotovelo do eqüino, conforme antímero e sexo.

\begin{tabular}{|c|c|c|c|c|}
\hline \multirow{2}{*}{ Variável (cm) } & \multicolumn{2}{|c|}{ Membro } & \multicolumn{2}{|c|}{ Sexo } \\
\hline & Direito $(n=10)$ & Esquerdo $(n=10)$ & Fêmea $(\mathrm{n}=10)$ & Macho $(n=10)$ \\
\hline Comprimento & $6,07 \pm 1,01$ & $6,08 \pm 0,99$ & $5,90 \pm 1,19$ & $6,30 \pm 0,86$ \\
\hline Largura & $1,52 \pm 0,370$ & $1,54 \pm 0,371$ & $1,34 \pm 0,21$ & $1,43 \pm 0,21$ \\
\hline
\end{tabular}

continuidade das fibras do ligamento oblíquo com a porção longa do ligamento colateral medial auxilia nessa função e estabiliza a articulação, juntamente com os outros ligamentos e o músculo extensor radial do carpo.

\section{CONCLUSÕES}

O ligamento oblíquo contribui no efeito mola e na manutenção da estabilidade da articulação do cotovelo do eqüino. Pela particularidade de sua localização, cranial à articulação, o ligamento oblíquo possui ação frenadora, impedindo a extensão completa da referida articulação.

\section{REFERÊNCIAS}

BENJAMIN, M.; RALPHS, J.R. Tendons and ligaments - an overview. Histology and Histopathology, v.12, p.1135$1144,1997$.

DYCE, K.M. et al. O membro anterior do eqüino. In: Tratado de anatomia veterinária. 2.ed. Rio de Janeiro: Guanabara Koogan, 1997. p.446-475.

FRANDSON, R.D. et al. Articulações. In: Anatomia e fisiologia dos animais de fazenda. 6.ed. Rio de Janeiro: Guanabara Koogan, 2005. p.77-88.
LIEBICH, H.-G.; KÖNIG, H.E. Membro anterior ou membro torácico (Membra thoracica). In: KÖNIG, H.E.; LIEBICH, H.-G. Anatomia dos animais domésticos: texto e atlas colorido. Porto Alegre: Artmed, 2002. v.1, p.133-201.

OLIVEIRA, D. Aspectos morfométricos e histológicos dos ligamentos colateral medial e oblíquo da articulação úmero-rádio-ulnar do cão (Canis familiaris). 2002. 54f. Dissertação (Mestrado em Cirurgia Veterinária) - Curso de Pósgraduação em Cirurgia Veterinária, Universidade Estadual Paulista.

OLIVEIRA, D. Contribuição biomecânica do ligamento oblíquo ao ligamento colateral medial da articulação do cotovelo de cães (Canis familiaris). 2004. 47f. Tese (Doutorado em Cirurgia Veterinária) - Curso de Pós-graduação em Cirurgia Veterinária, Universidade Estadual Paulista.

PAIVA, O.M. Efeito de mola dos gínglimos angulares perfeitos nos eqüídeos. O Veterinário, São Paulo, v.3, n.1, p.3-14, 1953.

SAS INSTITUTE. User's guide: stat. version 9.00. 4.ed. Cary, 2004. V.1.

SCHALLER, O. Artrologia. In: Nomenclatura anatômica veterinária ilustrada. São Paulo: Manole, 1999. p.76-97.

SISSON, S. Articulações do eqüino. In: GETTY, R. Sisson \& Grossman: anatomia dos animais domésticos. 5.ed. Rio de Janeiro: Guanabara Koogan, 1986. v.2, p.324-349. 